\title{
Impact of perinatal environmental health education intervention on exposure to endocrine disruptors during pregnancy - PREVED study: study protocol for a randomized controlled trial
}

Houria EL OUAZZANI ( $\nabla$ houria.el.fellah.el.ouazzani@univ-poitiers.fr)

Centre Hospitalier Universitaire de Poitiers https://orcid.org/0000-0003-1021-7134

Steeve ROUILLON

Centre Hospitalier Universitaire de Poitiers

Nicolas VENISSE

Centre Hospitalier Universitaire de Poitiers

Lynda SIFER-RIVIERE

Cermes3

Antoine DUPUIS

Centre Hospitalier Universitaire de Poitiers

Guillaume CAMBIEN

Centre Hospitalier Universitaire de Poitiers

Sarah AYRAUD-THEVENOT

Centre Hospitalier Universitaire de Poitiers

Anne-Sophie GOURGUES

Centre Hospitalier Universitaire de Poitiers

Pascale PIERRE-EUGENE

Centre Hospitalier Universitaire de Poitiers

Fabrice PIERRE

Centre Hospitalier Universitaire de Poitiers

Sylvie RABOUAN

Universite de Poitiers UFR Medecine et Pharmacie

Virginie MIGEOT

Centre Hospitalier Universitaire de Poitiers

Marion ALBOUY-LLATY

Centre Hospitalier Universitaire de Poitiers

Study protocol 
Keywords: Endocrine disruptors, Maternal exposure, Pregnancy, Environmental health, Intervention research

Posted Date: March 8th, 2021

DOI: https://doi.org/10.21203/rs.3.rs-51269/v1

License: (1) This work is licensed under a Creative Commons Attribution 4.0 International License. Read Full License

Version of Record: A version of this preprint was published at Trials on December 1st, 2021. See the published version at https://doi.org/10.1186/s13063-021-05813-5. 


\section{Abstract \\ Background}

The suspected or actual effects on health of Endocrine Disrupting Chemicals (EDC) and their ubiquitous presence in everyday life justify the implementation of health promotion interventions. These interventions should ideally apply during critical windows like pregnancy. Perinatal environmental health education interventions may help to reduce EDC exposure during pregnancy.

\section{Methods/Design}

PREVED (Pregnancy, PreVention, Endocrine Disruptors) is an open-label randomized controlled trial assessing the impact of environmental health education intervention on EDC exposure during pregnancy. Inclusion, consent and randomization take place during the first trimester. The participants are randomly allocated into three groups: i) control group (information leaflet on EDCs), ii) intervention group in neutral location (information leaflet and workshops in a meeting room) and iii) intervention group in contextualized location (information leaflet and workshops in a real apartment). Workshops are organized between the second and third trimesters of pregnancy. Main outcome is the percentage of participants who reported consuming manufactured/industrial food. Secondary outcomes are: i) psychosocial dimensions ii) EDC concentrations in urine iii) EDC concentration in colostrum and iv) percentage of participants who reported consuming paraben-free personal care products.

\section{Discussion}

PREVED is a ground-breaking intervention research project dedicated to perinatal environmental health education that aims to identify pollutant sources in daily life and to offer accessible and realistic alternative solutions, by promoting the sharing of know-how and experience in a positive and nonalarmist approach.

\section{Trial registration number}

ClinicalTrials.gov: NCT03233984 (current status: ongoing). Retrospectively registered on 31 July 2017 (https://clinicaltrials.gov/ct2/show/NCT03233984) because when the first participant was enrolled in this non-drug intervention, ClinicalTrials.gov was centred in therapeutic trials.

\section{World Health Organization Trial Registration Data Set:}

Additional file 1 


\section{Background}

The in utero period is an important period that conditions health in adult life. Prenatal exposure can disturb fetal and neonatal development [1] and lead to numerous disorders [2-4]. These health consequences are especially underlined by FOAD- (Fetal Origins of Adult Disease) [5], DOHaD(Developmental Origins of Health and Disease) theories [6, 7], which emphasize the importance of intrauterine environmental exposure in offspring health, and by POHaD-theory (Paternal Origins of Health and Disease), which underlines the role of paternal environment and exposure [8].

The concept of "exposome" initiated in the 2000s is along the same lines. Indeed, exposome includes lifetime exposures from periconceptional period until death [9]. Under this concept, exposures can be classified as $[10,11]$ :

- Internal exposure: combining all endogenous factors

- Specific external exposure: combining exogenous factors such as chemical contaminants, environmental pollutants and lifestyle factors

- General external exposure: taking into account a wider environment with social, economic and psychological factors

Among these exposure factors, Endocrine Disrupting Chemicals (EDCs) are chemicals and environmental pollutants defined by the World Health Organization (WHO) as "exogenous substances or mixture that alter function(s) of the endocrine system and consequently cause adverse health effects in an intact organism, or its progeny, or (sub)-populations" [12]. EDCs may be synthetic such as parabens (PB) and phthalates found in cosmetics, bisphenol A (BPA) found in plastics, or pesticides such as atrazine or trifluralin found in soil or food. They may also be natural such as hormones or phytoestrogens [13].

Their involvement is confirmed, or at least suspected, in the development of numerous diseases or disorders, especially on reproduction, hormone-dependent cancers $[14,15]$ and metabolic disorders [16]. This is typically the case of Diethylstilbestrol, an estrogen medication which was prescribed for pregnant women in the 1940s [17]. Many decades later, prenatal exposure to Diethylstilbestrol was recognized as the cause of many diseases for children exposed in utero, and even for grandchildren who had never been directly exposed [18-20]. In fact, exposure to several EDCs at specific developmental stages called "susceptibility" or "critical windows" such as prenatal and puberty periods, causes more pronounced health effects $[14,21,22]$.

In 2016, the European Commission made recommendations on prioritizing human epidemiology (followup cohorts...), knowledge about exposure (chemical markers, biomarkers...), and effects in wildlife [23], and in its strategic approach, issued in 2018, emphasis was put on prevention interventions, particularly in "critical windows" [24]. Thus, several steps were necessary to take into account EDC exposure [25].

Promotion health interventions should be carried out since the pre/periconceptional period [26], which comprises key moments of exposure sensitization and environmental health promotion $[27,28]$. There 
are numerous recommendations and interventions aimed at improving maternal and infant health, for instance, on nutrition [29-31], iron supplementation [32], physical activity [33], hypertensive disorders [34], oral health [29], or on reduction of environmental tobacco smoke exposure [35, 36]. However, only a few of them concern EDC exposure [37-40].

To our knowledge, there exists no research study focused on perinatal exposure through the prism of environmental health education in France. Our hypothesis was that an extended perinatal environmental health education intervention conducted during pregnancy by promoting the sharing of know-how and experience in a positive and non-alarmist approach would contribute to the reduction of EDC exposure.

The PREVED (Pregnancy, PreVention, Endocrine Disruptors) study aimed to assess the impact of an environmental health education intervention on prenatal exposure to EDCs. The secondary objectives are to assess the impact of the intervention on psycho-social dimensions, EDC concentration in urine and colostrum, and on the choice of personal care products. The EDCs studied are BPA, its chlorinated derivatives and PB: methyl-, ethyl-, propyl- and butyl-PB.

\section{Methods}

\section{Study design}

The PREVED study is an ongoing open-label, monocentric, randomized (1:1:1) controlled superiority trial, parallel-designed, three-armed with:

- A control group: Group (1)

- An intervention group in neutral location: Group (2)

- An intervention group in contextualized location: Group (3)

\section{Participants and interventions}

The PREVED study is conducted in Poitiers (France). Recruitment was held from April 2017 to April 2019. The site of intervention in an underprivileged and multicultural Poitiers neighborhood with strong associative potential (animation center, young workers' home and sports center), where women of low socioeconomic and educational status may be particularly exposed to EDCs [41].

According to the allocation group, workshops are performed in two different locations. Group (2)'s intervention is performed in a meeting room in the "Animation Centre of the neighborhood", which is a neutral location. Group (3)'s intervention is performed in "Atelier du 19", an apartment dedicated to health/environment education in everyday life [42].

Inclusion and exclusion criteria are detailed in Table 1. 
Table 1

Inclusion and Exclusion criteria for the PREVED study

\section{Inclusion criteria}

- pregnant women with declared pregnancy

- speaking French

- being aged 18 years or more

- living in the French department of Vienne and at less than 30 minutes from Poitiers

- having the intention to give birth in the maternity of the University Hospital, of the clinic "Fief de Grimoire" in Poitiers or in the Hospital of Châtellerault

- having signed a consent form

\section{Exclusion criteria}

- pregnant women expecting twins or more

- having a complicated pregnancy

- not speaking French

- being under 18 years old or under legal protection despite being 18 or more

- being deprived of liberty by judicial or administrative decision

- undergoing psychiatric treatment

- not being affiliated to a social security system

- intending to move out during the next year

- having the intention to give birth in a maternity ward other than the department of Vienne

- being unable to express consent

PREVED study implementation was preceded by an essential step involving pregnant women and professionals. Qualitative and quantitative studies were carried out to describe pregnant women's knowledge, attitudes and behaviors towards EDC exposure [43], to estimate their risk perception [44], and to determine environmental health knowledge, attitudes, and practices of prenatal healthcare providers [45]. These results facilitated the design of the intervention and the identification of the aims and outcomes of PREVED study.

Furthermore, the study was preceded by the creation of a "DisProSE Group" steering committee, a consortium of researchers, local actors and decision-makers which co-built the intervention, initially developed by a mutual insurance company, according to PREVED's aims and to behavior change techniques (BCT) taxonomy [46].

After complete recruitment, we could analyze the intervention, which involved 12 of the 16 BCTs, in view of diversifying approaches (Table 2). 
Table 2

Behavior change techniques (BCT) used for the intervention of PREVED study

\begin{tabular}{|c|c|c|}
\hline $\begin{array}{l}\text { Grouping of } \\
\text { BCT } \\
\text { taxonomy }\end{array}$ & $\begin{array}{l}\text { Chosen BCT in each BCT } \\
\text { group }\end{array}$ & Example of an intervention \\
\hline \multirow[t]{2}{*}{$\begin{array}{l}\text { Goals and } \\
\text { planning }\end{array}$} & Problem solving & $\begin{array}{l}\text { - Aim of the study: to reduce personal exposure to } \\
\text { endocrine disruptors chemicals (EDC) }\end{array}$ \\
\hline & Action planning & - Make one's own cosmetics at home \\
\hline $\begin{array}{l}\text { Feedback and } \\
\text { monitoring }\end{array}$ & Not applicable & $\begin{array}{l}\text { - No feedback between the workshops/Only a series of } \\
\text { workshops by participant }\end{array}$ \\
\hline Social support & Not applicable & - Few attendants came to the workshops \\
\hline \multirow[t]{2}{*}{$\begin{array}{l}\text { Shaping } \\
\text { knowledge }\end{array}$} & $\begin{array}{l}\text { Training on how to } \\
\text { perform the behavior }\end{array}$ & $\begin{array}{l}\text { - Read labels on packaging/Teach how to prepare one's } \\
\text { own cookies and cosmetics at home }\end{array}$ \\
\hline & Behavioral experiments & - Follow the evolution of one's own knowledge \\
\hline \multirow[t]{2}{*}{$\begin{array}{l}\text { Natural } \\
\text { consequences }\end{array}$} & $\begin{array}{l}\text { Information about health } \\
\text { consequences }\end{array}$ & $\begin{array}{l}\text { - Link between exposure to EDC during pregnancy and } \\
\text { pregnancy outcomes (answers to participants' } \\
\text { questions, no listing of effects) }\end{array}$ \\
\hline & $\begin{array}{l}\text { Information about social } \\
\text { and environmental } \\
\text { consequences }\end{array}$ & $\begin{array}{l}\text { - Use of natural solid soap and not leaving it wet after } \\
\text { use }\end{array}$ \\
\hline $\begin{array}{l}\text { Comparison } \\
\text { of behavior }\end{array}$ & $\begin{array}{l}\text { Demonstration of the } \\
\text { behavior }\end{array}$ & - Teach how to make one's own cosmetics \\
\hline Associations & Prompts/clues & - Leaflets and documentation \\
\hline \multirow{6}{*}{$\begin{array}{l}\text { Repetition } \\
\text { and } \\
\text { substitution }\end{array}$} & $\begin{array}{l}\text { Behavioral } \\
\text { practice/rehearsal }\end{array}$ & - Teach how to make one's own cosmetics \\
\hline & Behavior substitution & $\begin{array}{l}\text { - Avoid heating food in plastic dishes with a microwave } \\
\text { oven }\end{array}$ \\
\hline & Habit formation & - Air out the house \\
\hline & Habit reversal & - Use glass packaging instead of plastic packaging \\
\hline & $\begin{array}{l}\text { Generalization of target } \\
\text { behavior }\end{array}$ & $\begin{array}{l}\text { - Teach how to make one's own cosmetics in order to be } \\
\text { independent/Repeat the manufacture at home }\end{array}$ \\
\hline & Graded tasks & $\begin{array}{l}\text { - "Change everything" is neither taught nor } \\
\text { required/Propose simple solutions to reduce exposure } \\
\text { to EDC }\end{array}$ \\
\hline \multirow{2}{*}{$\begin{array}{l}\text { Comparison } \\
\text { of outcomes }\end{array}$} & Credible source & - Use of current data from literature \\
\hline & Pros and cons & $\begin{array}{l}\text { - Using glass packaging instead of plastic packaging is } \\
\text { valuable but not without some constraints. }\end{array}$ \\
\hline
\end{tabular}




\begin{tabular}{|c|c|c|}
\hline $\begin{array}{l}\text { Grouping of } \\
\text { BCT }\end{array}$ & $\begin{array}{l}\text { Chosen BCT in each BCT } \\
\text { group }\end{array}$ & Example of an intervention \\
\hline & $\begin{array}{l}\text { Comparative imagining } \\
\text { of future outcomes }\end{array}$ & $\begin{array}{l}\text { - Projection of creative thinking/projecting oneself in } \\
\text { one's accommodation by eliminating sources of EDC }\end{array}$ \\
\hline \multirow[t]{2}{*}{$\begin{array}{l}\text { Reward and } \\
\text { threat }\end{array}$} & \multirow[t]{2}{*}{ Material reward } & $\begin{array}{l}\text { - Participants in group (2) and group (3) took home } \\
\text { what they made in workshop }\end{array}$ \\
\hline & & $\begin{array}{l}\text { - Compensation for transportation costs to participants } \\
\text { in group (2) and group ( } 3 \text { ) was envisioned but not } \\
\text { possible }\end{array}$ \\
\hline Regulation & $\begin{array}{l}\text { Conserving mental } \\
\text { resources }\end{array}$ & $\begin{array}{l}\text { - Pleasure of consumption of healthy products is } \\
\text { recalled }\end{array}$ \\
\hline Antecedents & $\begin{array}{l}\text { Adding objects to the } \\
\text { environment }\end{array}$ & $\begin{array}{l}\text { - Pregnant women bring to their house what they made } \\
\text { in workshops: floor cleanser (with black soap), cookies, } \\
\text { liniment, deodorant }\end{array}$ \\
\hline \multirow[t]{3}{*}{ Identity } & Framing/reframing & $\begin{array}{l}\text { - Presentation of a positive vision of health/Do not } \\
\text { focus on pathologies }\end{array}$ \\
\hline & \multirow[t]{2}{*}{ Incompatible beliefs } & $\begin{array}{l}\text { - Use of cosmetics containing parabens is not healthy } \\
\text { behavior }\end{array}$ \\
\hline & & $\begin{array}{l}\text { - "Natural product" does not mean "Safe product" or } \\
\text { "Healthy product" on labels }\end{array}$ \\
\hline $\begin{array}{l}\text { Scheduled } \\
\text { consequences }\end{array}$ & Not applicable & \\
\hline \multirow[t]{2}{*}{ Self-belief } & $\begin{array}{l}\text { Verbal persuasion about } \\
\text { capability }\end{array}$ & $\begin{array}{l}\text { - Highlight simple and accessible solutions to limit } \\
\text { exposure to EDC/positive reinforcement between } \\
\text { participants }\end{array}$ \\
\hline & Focus on past success & - Sharing of practices between participants \\
\hline $\begin{array}{l}\text { Covert } \\
\text { learning }\end{array}$ & Not applicable & \\
\hline
\end{tabular}

None concomitant intervention is prohibited. Women randomized in the control group are told that they are entitled to have the program after the end of the study (one year after delivery).

The list of pregnant women is obtained through pregnancy declarations, which are centralized in France by "Protection Maternelle et Infantile" (maternal and child protection) or PMI. The investigator sends to eligible women an informative postal mail with a prepaid envelope. Women who wished to participate in PREVED study confirmed their interest by phone or mail.

To improve enrolment, information leaflets are sent to general practitioners and midwives working in the enrolment area. To achieve representative and adequate enrolment, PMI's midwives were trained to 
present the PREVED study to pregnant women. Local actors in social centers and the associative sector also assisted in enrolment. The first participant was enrolled on 17 April 2017.

The intervention consisted of a sequence of three workshops held between the second and the third trimesters of pregnancy. It incorporated the results of a previous workshop [43] and aimed to identify pollutant sources in daily life and to offer accessible and pragmatic alternative solutions by promoting the sharing of know-how and experience in a positive and non-alarmist approach. Three themes are addressed (Table 3). Any participant may at any time withdraw from this study and adherence participation is encouraged with adapted meeting.

DisProSE group produced an information leaflet providing advice on ways of reducing EDC exposure in relation to the aforementioned themes. This leaflet was designed according to the principles of health literacy to be as accessible and comprehensible as possible [47]. All participants, including Group (1), receive it during the first home visit. The only difference between Group (2)'s workshops and Group (3)'s workshops is the location of the intervention.

Figure 1 summarizes the conduct of PREVED study.

Table 3

Detailed workshops for the intervention of PREVED study

\begin{tabular}{|llll|}
\hline & Workshop 1 & Workshop 2 & Workshop 3 \\
\hline Theme & Indoor air quality & Nutrition & Personal care products \\
\hline Duration & 2 hours & 2 hours & 2 hours \\
\hline Participants & $\begin{array}{l}\text { 10 people: pregnant } \\
\text { women } \pm \text { spouse, } \\
\text { friend or parent }\end{array}$ & $\begin{array}{l}\text { 10 people: pregnant } \\
\text { women } \pm \text { spouse, friend } \\
\text { or parent }\end{array}$ & $\begin{array}{l}10 \text { people: pregnant women } \pm \\
\text { spouse, friend or parent }\end{array}$ \\
\hline Facilitator & $\begin{array}{l}\text { Medical advisor for } \\
\text { indoor environments }\end{array}$ & $\begin{array}{l}\text { Dietician trained in } \\
\text { environmental health }\end{array}$ & Cosmetologist \\
\hline $\begin{array}{l}\text { Pedagogic } \\
\text { objectives }\end{array}$ & $\begin{array}{l}\text { - To detect and reduce } \\
\text { sources of domestic } \\
\text { air pollution }\end{array}$ & $\begin{array}{l}\text { - To identify food } \\
\text { pollutants }\end{array}$ & $\begin{array}{l}\text { - To identify necessary elements } \\
\text { to make healthy choices of } \\
\text { personal care products and } \\
\text { clothes }\end{array}$ \\
& $\begin{array}{l}\text { - To share know-how, } \\
\text { experiences and } \\
\text { information on } \\
\text { alternatives }\end{array}$ & $\begin{array}{l}\text { - To share know-how, } \\
\text { experiences and } \\
\text { information on } \\
\text { alternatives }\end{array}$ & $\begin{array}{l}\text { - To share know-how, } \\
\text { experiences and information on } \\
\text { alternatives }\end{array}$ \\
\hline
\end{tabular}

Main outcome:

- Percentage of participants who reported consuming manufactured or industrial food determined through a sociodemographic and consumption questionnaire (Q1) developed by our research team [48]

Secondary outcomes: 
- Mean score of psychosocial questionnaire (Q2) developed by our team, whose dimensions are presented in Table 4

- Urinary concentrations of: BPA, chlorinated derivatives of BPA, methyl-, ethyl-, propyl- and butyl-PB

- Concentration in colostrum of: BPA, methyl-, ethyl-, propyl- and butyl-PB

- Percentage of participants who reported consuming PB-free personal care products 
Table 4

Dimensions of the psychosocial questionnaire used in PREVED study

\section{Dimension of the psychosocial questionnaire}

\section{Origin of corresponding question or questions}

Self-esteem
French version of the "Self-esteem scale" [49]

\section{Comment}

Score ranges from 10 to 40 : the lower the score, the lower selfesteem. Items for this score are selfadministered

Perceived Health

Created for the questionnaire

Score ranges from 0 to 100 on a visual analogic scale

Health care renunciation and risk aversion

Inspired by French national Use of visual analogic scales investigations $[50$, 51]

Risk perception

Created for the questionnaire and based on the Perception of Pregnancy Risk Questionnaire [52]

Knowledge about Endocrine Disrupting Chemicals (EDCs): routes and sources of exposure, ability to name some EDC's molecules or families of molecules and definition of an EDC

Perceived knowledge about EDCs

Expectations for a "healthy baby"

Trusted person

Level of concern about five risks related to pregnancy

The way the pregnant woman heard about EDCs and, if so, how she experienced the information she received
Created for the questionnaire
Created for the questionnaire

Based on "the healthy baby concept" [53]

Created for the questionnaire

Created for the

Created for the questionnaire questionnaire
Use of visual analogic scales. A composite and global score of perinatal risk perception related to EDC exposure was created

A composite score was created. A catalogue of photo images illustrates sources of exposure
Use of a visual analogic scale

Use of a visual analogic scale and a catalogue of photo images

The answer to this question aims to identify the trusted person, who exerts the most influence on the pregnant woman

This exploration is meant to establish a hierarchy, with respect to chemical risk concerns. A catalogue of photo images is used

These two parameters explore the role of information provided by the media, professional studies, and relationships (personal, friendly, professional, health professionals) 


\begin{tabular}{|lll|}
\hline $\begin{array}{l}\text { Dimension of the psychosocial } \\
\text { questionnaire }\end{array}$ & $\begin{array}{l}\text { Origin of } \\
\text { corresponding } \\
\text { question or } \\
\text { questions }\end{array}$ & Comment \\
\hline Relationship to risk visibility & $\begin{array}{l}\text { Created for the } \\
\text { questionnaire }\end{array}$ & Likert-type response \\
\hline
\end{tabular}

The planning of the administration of questionnaires and the collection of samples is summarized in Fig. 2.

Time schedule of enrolment, intervention, assessments and visits are detailed in Table 5. They were carried out according to the SPIRIT Guideline (Additional file 2). 
Table 5

SPIRIT Flow Diagram of schedule of enrolment, interventions, and assessments in PREVED study

Enrolment Post-allocation

Closeout

TIMEPOINT

$\begin{array}{llllll}\text { Baseline } & t_{0} & t_{+1 M} & t_{+2 M} & t_{+4 M} & t_{+14 M} \\ \begin{array}{l}\text { Home } \\ \text { visit 1 }\end{array} & \text { Childbird } & \begin{array}{l}\text { Home } \\ \text { visit 2 }\end{array} & \begin{array}{l}\text { Home } \\ \text { visit 3 }\end{array} \\ & \text { Leaflet } & \text { Workshops } & & & \end{array}$

ENROLMENT:

Eligibility screen

$X$

Informed consent

$\mathrm{X}$

Allocation

$\mathrm{X}$

\section{INTERVENTIONS:}

Group 1

X

Control group

Group 2

$x \quad x$

Intervention group in

Neutral location

Group3

$x \quad x$

Intervention group in

Contextualized location

ASSESSMENTS:

Q1

$\mathrm{X}$

$\mathrm{X}$

$x$

Sociodemographic

questionnaire +

Consumption habits

Q2

X

$\mathrm{X}$

X

Psychosocial questionnaire

Collection of urine samples

$x$

$\begin{array}{llll}x & x & x \\ x & \end{array}$

Colostrum samples

\section{Sample size}


According to the results of the EDDS (Endocrine Disruptors Deux-Sèvres) cohort study, $83 \%$ of French women consumed canned food [48]. Thus, we calculated the number of participants based on the primary outcome measure (consumption measure) using a two-sided paired sample t-test with 0.05 level of significance two-way design and $\beta=0.20$. Our hypothesis was that the contextualized intervention would decrease this percentage to $60 \%$, representing a decrease of 23 points, and 58 participants were required for each group. We expected $20 \%$ of lost to follow-up participants; consequently, 70 participants are required for each group, out of a total of 210 pregnant women to be included in our study. This number was increased to 273 persons due to significant colostrum loss in an amendment submitted to the Committee for Personal Protection who approved the first protocol (protocol version 10 approved by the Committee for Personal Protection on 15 June 2018).

\section{Assignment of interventions}

The trial is open-labelled but a random blind-generated allocation with 1:1:1 ratio is based on fixed blocks of 3 before the first home visit. The allocation sequence is generated on Microsoft EXCEL ${ }^{\circledR}$ (function RAND) by a doctoral student. The methodological referent of PREVED study enrolled the participants. Participants are then randomly assigned to one of the three groups by a research nurse who is also trained in indoor environments.

This type of study design did not allow a blinded trial as is the case in intervention research.

None modification of assignment was done.

\section{Data collection, management and analysis}

The research nurse performs home visits and collected data at four key moments (Table 5):

- Home visit 1: Q1, Q2 and urine analysis

- Home visit 2: Q1, Q2 and urine analysis

- Childbirth: childbirth data, urine and colostrum analysis

- Home visit 3: Q1 and Q2

- Data input is entered by the research nurse and by the study site coordinator on electronic Case Report Forms (e-CRF). Quality control and queries are carried out regularly. Telephone reminders are expected, if necessary, for Home visits 2 and 3.

Urine and colostrum samples are collected in glassware provided by the investigator. They are stored at $-80^{\circ} \mathrm{C}$, in polypropylene tubes, in the Biological Resource Centre of the University Hospital of Poitiers (no. BB-0033-00068) for five years. This samples are analyzed using reliable ultrasensitive methods previously developed by our research team for BPA and its chlorinated derivatives $[54,55]$ and new methods for PB developed for this study. All laboratory materials and solvents are tested to ensure that they were free of contamination from target compounds. High-quality compounds and solvents are supplied by reagent manufacturers. Samples are prepared and extracted. Analyte concentrations are determined using Ultra Performance Liquid Chromatography (Shimadzu® ${ }^{\circledR}$, Kyoto, Japan) coupled to an 
API 6500 + mass spectrometer (ABSciex®, Concord, Canada) equipped with an electrospray ionization (ESI) interface, operating in negative ionization mode. Target analytes are analyzed in multiple-reaction monitoring (MRM) mode using two specific transitions per analyte to ensure the selectivity and the sensitivity of the method. The analytical methods used are validated according to international guidelines [56-59]. These methods allow to detect and quantify trace concentrations of unconjugated forms of BPA, its chlorinated derivatives and PB. Urinary concentrations of analytes are corrected using urinary creatinine concentrations determined with a Cobas ${ }^{\circledR} 8000$ (Roche Diagnostics, Mannheim, Germany) and using urinary specific gravity determined with a hand-helded refractometer.

Firstly, a descriptive analysis will be performed on sociodemographic data, questionnaire scores and on EDC concentrations with percentage for qualitative variables and mean, standard deviation, median, maximum and minimum for quantitative variables.

Baseline measurements of the three trial arms will be compared using paired t-tests and $\chi 2$-tests for the analysis of Q1 and EDC concentrations. The results of Q2 in the three groups will be compared by dimension using ANOVA analyses. A intention-to-treat analysis will carried out and then a per-protocol analysis in aim to take into account population relating to protocol non-adherence.

Main outcome will be compared between Home visit 1 and Home visit 2. The rest of analysis will be performed between Home visit 1, Home visit 2 and Home visit 3. Multivariate logistic regression will be performed to assess factors influencing main and secondary outcomes.

All statistical analyses will be performed using SAS 9.4® (SAS Institute, Cary, North Carolina, USA).

No interim analyses are scheduled.

\section{Monitoring}

A data monitoring committee was composed by a team from the Research Directorate of University Hospital of Poitiers. It is in charge of auditing trial conduct every 4 months, data management and promoting data quality. It consists of a Clinical Research Associate, a project monitoring manager, a data manager and also the clinical trials vigilance unit. Consistency tests were performed on e-CRFs. As the study carries no risk, only consent and reporting of serious adverse events are verified. The only expected adverse event was anxiety. Adverse events are noted at each home visit, throughout the period of participation of pregnant women.

\section{Discussion}

To our knowledge, PREVED is the first study to assess the impact of perinatal environmental health education by promoting the sharing of know-how and experience in a positive and non-alarmist approach. Along with the randomized controlled trial, a sociological approach is applied to analyze the conditions of Reach, Efficacy, Adoption, Implementation and Maintenance of the intervention [60]. In particular, observations are carried out during the workshops using grids and describing the interactions 
between the pregnant women and the workshop animator [61]. Moreover, interviews with stakeholders (researchers, local actors and decision-makers) are conducted to evaluate the transferability of the intervention. The collective and local dynamics underlying the development of intervention and the points of view of participants are thereby assessed [61].

The PREVED study adopted two complementary approaches in the framework of the intervention research process. In fact, intervention research applied to the health field is a specific kind of research that aims to provide information on the impact of interventions on population health using scientific methods [63] and to determine how "to intervene" (not "to discover") [64]. This design should be wellfounded and include partnerships with practitioners [65]. Thus, DisProSE group facilitated partnership with different stakeholders through an interdisciplinary approach.

The PREVED intervention takes on the form of practical two-hour workshops. This configuration is easily reproducible and viable. Indeed, in addition to mention of the effectiveness of intervention research, degree of viability and specification of the mechanisms explaining the effects should be considered in conjunction with "the interventional system" [66].

Furthermore, the main feature of PREVED study is to consider all aspects of lifestyle and to underscore key functions such as sharing of know-how, sharing of experiences and information between participants. Indeed, few environmental promotion interventions have shown that EDC exposure was reduced by changing lifestyle. However, previous studies assessed the impact by taking into account only one component of lifestyle, such as nutrition or cosmetics $[67,68]$ and did not include the dimension of "know-how" [69]. Moreover, these studies took EDC concentrations in urine as their main outcome, even though analysis of the latter may be unreliable [70-72] and did not provide information about psychosocial aspects. This facet will be explored by the psychosocial questionnaire Q2 in our study. Concerning exposure assessment to EDCs, we chose urine matrix samples because spot samples of urines are not restrictive and ensure optimal acceptability for the pregnant women participating. Twentyfour-hour urine collection may have been preferable, due to non-influence of the time of day. However, spot samples of urines provide reasonably reliable information on impregnation by BPA and PB during pregnancy [73-76].

We made sustained efforts to minimize information bias. Notwithstanding, the absence of blindness, the investigator's practices and behaviors are likely to vary during visits, according to allocation group. That is why hetero-administration of questionnaires by a single trained assessor, with a standardized interviewer's guide, has been adopted. Furthermore, selection bias is controlled by trained PMI nurses wishing to facilitate the enrolment of pregnant women facing difficulties. Enrolment bias is thereby avoided, whereas preceding studies highlighted the fact that participants for this type of study are mostly women with a high socio-economic level [48]. However, in such a cohort, selection bias can still be expected [77] especially for pregnancy cohorts, insofar as women with a high socio-educational level are likely to feel more concerned $[78,79]$. We will probably need to determine how to more effectively reach 
populations in precarious situations. At the time of the analysis, results will be adjusted on confounding factors that affect the psycho-social dimensions and have been highlighted in this study.

\section{Conclusion}

Through this study, we aspire to increase all health stakeholders' awareness of the importance of primary prevention on exposome, especially EDC exposure, during pregnancy. In fact, given the methodological difficulties in proving EDC's effects in humans, some authors are convinced that it is impossible to conclusively demonstrate, and they would rather think in terms of prevention actions. That is why research studies should be complemented by interventions designed to reduce EDC exposure, such as primary prevention interventions, notably during pregnancy and other critical windows $[28,80,81]$. This approach also provides the scientific community and decision makers with elements possibly reinforcing their commitment to environmental health promotion.

\section{Trial Status}

Since the last recruitment took place in the end of 2019, the last visit will be planned in the end of 2020 .

The choice to publish the study protocol after recruitment completion but before the last visit can be justified by the particularity of population health intervention research.

In fact, this kind of study design integrated an "interventional system" as defined by Cambon $L$ et al. as "a set of interrelated human and non-human contextual agents within spatial and temporal boundaries generating mechanistic configurations - mechanisms - which are prerequisites for change in health" [82]. Hence this "interventional system" required continuous adjustment to the intervention context. That is why theorization of the methodology, and consequently of the protocol, requires more time than a classic therapeutic trial. As a result, we had to step back after the intervention and integrate the dynamism of the interventional system in order to improve the quality of our assessment.

\section{Abbreviations}

ANOVA

Analysis of variance

BCT

Behavior Change Techniques

BPA

Bisphenol A

DOHaD

Developmental Origins of Health and Disease

e-CRF

electronic Case Report Forms 
EDC

Endocrine Disrupting Chemical

EDDS

Endocrine Disruptors Deux-Sèvres

ESI

electrospray ionization

FOAD

Fetal Origins of Adult Disease

MRM

Multiple-Reaction Monitoring

PB

Parabens

PMI

Protection Maternelle et Infantile

POHaD

Paternal Origins of Health and Disease

WHO

World Health Organization

\section{Declarations}

\section{Ethics approval and consent to participate}

PREVED study is sponsored by the University Hospital of Poitiers (Contact: Véronique FERRANDRIGALLAUD). The methodological referent obtained informed consents signed by all participants.

Pregnant women are free to leave the study at any time. Additional informed consents were developed for collection and use of additional data and biological specimens for two ancillary studies which were also approved:

- PREVED microbiota

- PREVED placenta

This trial has been approved by Ethics Committee of the University Hospital of Poitiers, France: approval no. 2015-18 RR/MLB/LB and Committee for Personal Protection (CPP) - Ouest III: approval no. 2015A00031-48 (HPS). It was registered on the Clinical Trials website, ClinicalTrials.gov (NCT03233984).

Results will be published in a peer-reviewed journal. This protocol follows SPIRIT guidelines.

\section{Consent for publication}

Not applicable. 
Availability of data and materials

Paper questionnaires will be automatically anonymized to be entered on e-CRF anonymously, and then stored in a locked cupboard. Biological samples will be identified only by the anonymity code.

The data sets generated and analyzed during this study are not publicly available. The methodological referent and the doctoral student will have access to the final trial dataset and results will be published in a peer-reviewed journal in 2021 with a defined authoship (Additional file 3). As of now, data have yet to be analyzed.

\section{$\underline{\text { Competing interests }}$}

The authors declare that they have no competing interests.

\section{Funding}

The "Fondation de France" brought its financial support for this study by grant no. 201500060744. This grant made possible the financing of data collection, the sociological study and also the analysis of urine and colostrum samples. "Fondation de France" had no role in the collection, management, analysis and interpretation of data, nor in writing of report and decision to submit it for publication. Also, we intend to respond to call for proposals in order to disseminate the study's results via seminars and workshops, and to fund the monitoring of the cohort ("PREVED children").

\section{Authors' contributions:}

This work is the result of numerous collaborations and exchanges. St.Ro., M.A.-L., V.M., Sy.Ra. designed the protocol. St.Ro., M.A.-L., V.M., Sy.Ra., H.E.-O and DisProSE Group participated in design and validation of the intervention. A.-S.G. and F.P. recruited the women who participated in PREVED study. M.A-.L. and L.S.-R. supervised the human and social sciences approach. St.Ro. and M.A.-L. designed the questionnaires. St.Ro., A.D. and N.V. developed analytical methods for determination of EDCs in urine and colostrum. A.-S.G. was the research nurse of PREVED study. G.C and P.P.E contributed to sample analysis. H.E.-O, St.Ro. and M.A.-L. wrote the paper. H.E.-O and St.Ro contributed equally to this work.

\section{Acknowledgements:}

The authors thank the Biological Resource Centre of the University Hospital of Poitiers (no. BB-003300068) for storing samples. They would like to thank Adeline Valliccioni, midwife student, Nathalie Morin from “Mutualité française Poitou-Charentes", Christophe Malvault from IREPS and Sylvie Bonniol from PMI. The authors would like to thank ARS and DREAL Nouvelle-Aquitaine for their support. They also thank Jimmy Ardouin (J.A.), Amélie Cant, Camille Gatien and Alexia Koudou, Master students at the University of Poitiers for their active contributions to the focus group and its analysis.

The authors thank Sandy Bertin, Louise Mignet and Marion Gorgun for their participation in administration of the questionnaire. They would like to thank the DisProSE Group: Celine Airaud, Marion 
Albouy-Llaty, Lydie Ancelot, Christine Berthome, Sylvie Bonniol, Delphine Charier, Yves Cottet, Marc-Hubert Depret, Marie-Laure Guillemot, Jean-Benoit Hardouin, Helene Le Turdu, Christophe Malvault, Virginie Migeot, Nathalie Morin, François Nivault, Sylvie Rabouan, Lynda Sifer-Rivière. The authors would also like to thank Jean-Benoit Hardouin and Line Enjalbert for their contribution to the validation of the psychosocial questionnaire.

We wish to thank the participating maternities for their help in the recruitment of pregnant women. We likewise wish to thank the participating pregnant women. Finally, we would like to thank Jeffrey Arsham, American English native speaker and English teacher at the University of Poitiers, for his help in preparation of the English version of this publication.

\section{References}

1. Chianese R, Troisi J, Richards S, Scafuro M, Fasano S, Guida M, Pierantoni R, Meccariello R. Bisphenol A in Reproduction: Epigenetic Effects. Curr Med Chem. 2018 Feb 21;25(6):748-770.

2. Darbre PD. Endocrine Disruptors and Obesity. Curr Obes Rep. 2017 Mar;6(1):18-27.

3. Rivollier F, Krebs MO, Kebir O. Perinatal Exposure to Environmental Endocrine Disruptors in the Emergence of Neurodevelopmental Psychiatric Diseases: A Systematic Review. Int J Environ Res Public Health. 2019 Apr 12;16(8).

4. Von Ehrenstein OS, Ling C, Cui X, Cockburn M, Park AS, Yu F, Wu J, Ritz B. Prenatal and infant exposure to ambient pesticides and autism spectrum disorder in children: population based casecontrol study. BMJ. 2019 Mar 20;364:1962. doi: 10.1136/bmj.I962. Erratum in: BMJ. 2019 Jun 25;365:14032.

5. Skogen JC, Overland S. The fetal origins of adult disease: a narrative reviewof the epidemiological literature. JRSM Short Rep. 2012 Aug;3(8):59.

6. Wadhwa PD, Buss C, Entringer S, Swanson JM. Developmental origins of health and disease: brief history of the approach and current focus on epigenetic mechanisms. Semin Reprod Med. 2009 Sep;27(5):358-68.

7. Newnham JP. The developmental origins of health and disease ( $\mathrm{DOHaD})$ - why it is so important to those who work in fetal medicine. Ultrasound Obstet Gynecol. 2007 Feb;29(2):121-3.

8. Soubry A. POHaD: why we should study future fathers. Environ Epigenet. 2018 Apr 26;4(2):dvy007.

9. Wild CP. Complementing the genome with an "exposome": the outstanding challenge of environmental exposure measurement in molecular epidemiology. CancerEpidemiol Biomarkers Prev. 2005 Aug;14(8):1847-50.

10. Wild CP. The exposome: from concept to utility. Int J Epidemiol. 2012 Feb;41(1):24-32.

11. Varshavsky J, Smith A, Wang A, Hom E, Izano M, Huang H, Padula A, Woodruff TJ. Heightened susceptibility: A review of how pregnancy and chemical exposures influence maternal health. Reprod Toxicol. 2019 May 2. pii: S0890-6238(18)30434-9. 
12. World Health Organisation. Global assessment of the state-of-the-science of endocrine disruptors. Chapter 1: Executive Summary. 2015. Available from: http://www.who.int/ipcs/publications/new_issues/endocrine_disruptors/en/ [Accessed 27 Jul2020].

13. Kabir ER, Rahman MS, Rahman I. A review on endocrine disruptors and their possible impacts on human health. Environ Toxicol Pharmacol. 2015 Jul;40(1):241-58.

14. Fenichel P, Brucker-Davis F, Chevalier N. Perturbateurs endocriniens - Reproduction et cancers hormono-dépendants [Endocrine disruptors, reproduction and hormone-dependent cancers]. Presse Med. 2016 Jan;45(1):63-72.

15. Lauretta R, Sansone A, Sansone M, Romanelli F, Appetecchia M. Endocrine Disrupting Chemicals: Effects on Endocrine Glands. Front Endocrinol (Lausanne). 2019 Mar 21;10:178.

16. Heindel JJ, Blumberg B, Cave M, Machtinger R, Mantovani A, Mendez MA, Nadal A, Palanza P, Panzica G, Sargis R, Vandenberg LN, Vom Saal F. Metabolism disrupting chemicals and metabolic disorders. Reprod Toxicol. 2017 Mar;68:3-33.

17. Tournaire M, Epelboin S, Devouche E. [Diethylstilbestrol story]. Therapie. 2014 Jan-Feb;69(1):101-14.

18. Fénichel P, Brucker-Davis F, Chevalier N. The history of Distilbène ${ }^{\circledR}$ (Diethylstilbestrol) told to grandchildren-the transgenerational effect. Ann Endocrinol (Paris). 2015 Jul;76(3):253-9.

19. Hatch EE, Troisi R, Palmer JR, Wise LA, Titus L, Strohsnitter WC, Ricker W, Hyer M, Hoover RN. Prenatal diethylstilbestrol exposure and risk of obesity in adult women. J Dev Orig Health Dis. 2015 Jun;6(3):201-7.

20. Diethylstilbestrol (DES): also harms the third generation. Prescrire Int. 2016 Dec;25(177):294-298.

21. Mallozzi M, Bordi G, Garo C, Caserta D. The effect of maternal exposure to endocrine disrupting chemicals on fetal and neonatal development: A review on the major concerns. Birth Defects Res $C$ Embryo Today. 2016 Sep;108(3):224-242.

22. Wright RO. Environment, susceptibility windows, development, and child health. Curr Opin Pediatr. 2017 Apr;29(2):211-217.

23. European commission. Conclusions and recommendations. Last updated: 08/06/2016. Available from:

http://ec.europa.eu/environment/chemicals/endocrine/documents/reports_conclusions_en.htm [Accessed 27 Jul 2020].

24. European Commission. Communication from the commission to the european parliament, the council, the european economic and social committee and the committee of the regions. Towards a comprehensive European Union framework on endocrine disruptors. Brussels, 7.11.2018. COM(2018) 734 final. Available from: http://ec.europa.eu/transparency/regdoc/rep/1/2018/EN/COM-2018-734F1-EN-MAIN-PART-1.PDF [Accessed 27 Jul 2020].

25. Gee D. Late lessons from early warnings: Toward realism and precaution with endocrine-disrupting substances. Environ Health Perspect. 2006 Apr;114 Suppl 1:152-60.

26. Stephenson J, Fleming TP, Godfrey KM, Barker M. Preconception health - Authors' reply. Lancet. 2018 Nov 24;392(10161):2267. doi: 10.1016/S0140-6736(18)32169-X. 
27. Heindel JJ, Vandenberg LN. Developmental origins of health and disease: a paradigm for understanding disease cause and prevention. Curr Opin Pediatr. 2015 Apr;27(2):248-53.

28. Grason HA, Misra DP. Reducing exposure to environmental toxicants before birth: moving from risk perception to risk reduction. Public Health Rep. 2009 Sep-Oct;124(5):629-41.

29. Fitzsimons D, Dwyer JT, Palmer C, Boyd LD. Nutrition and oral health guidelines for pregnant women, infants, and children. J Am Diet Assoc. 1998 Feb;98(2):182-6, 189; quiz 187-8.

30. Bhutta ZA, Das JK, Rizvi A, Gaffey MF, Walker N, Horton S, Webb P, Lartey A, Black RE; Lancet Nutrition Interventions Review Group, the Maternal and Child Nutrition Study Group. Evidence-based interventions for improvement of maternal and child nutrition: what can be done and at what cost? Lancet. 2013 Aug 3;382(9890):452-477.

31. Koletzko B, Godfrey KM, Poston L, Szajewska H, van Goudoever JB, de Waard M, Brands B, Grivell RM, Deussen AR, Dodd JM, Patro-Golab B, Zalewski BM; EarlyNutrition Project Systematic Review Group. Nutrition During Pregnancy, Lactation and Early Childhood and its Implications for Maternal and Long-Term Child Health: The Early Nutrition Project Recommendations. Ann Nutr Metab. 2019;74(2):93-106.

32. Siu AL; U.S. Preventive Services Task Force. Screening for Iron Deficiency Anemia and Iron Supplementation in Pregnant Women to Improve Maternal Health and Birth Outcomes: U.S. Preventive Services Task Force Recommendation Statement. Ann Intern Med. 2015 Oct 6;163(7):52936.

33. Oliveira C, Imakawa TDS, Moisés ECD. Atividade física durante a gestação: recomendações e ferramentas de avaliação [Physical Activity during Pregnancy: Recommendations and Assessment Tools] [Abstract]. Rev Bras Ginecol Obstet. 2017 Aug;39(8):424-432. doi: 10.1055/s-0037-1604180. Epub 2017 Aug 7. Review. Erratum in: Rev Bras Ginecol Obstet. 2017 Oct;39(10):584.

34. Brown MA, Magee LA, Kenny LC, Karumanchi SA, McCarthy FP, Saito S, Hall DR, Warren CE, Adoyi G, Ishaku S; International Society for the Study of Hypertension in Pregnancy (ISSHP). Hypertensive Disorders of Pregnancy: ISSHP Classification, Diagnosis, and Management Recommendations for International Practice. Hypertension. 2018 Jul;72(1):24-43.

35. Sahebi Z, Kazemi A, Loripour M, Shams N. An educational intervention to men for reducing environmental tobacco smoke exposure in their pregnant wives. J Matern Fetal Neonatal Med. 2019 May;32(10):1595-1601.

36. Risica PM, Gavarkovs A, Parker DR, Jennings E, Phipps M. A tailored video intervention to reduce smoking and environmental tobacco exposure during and after pregnancy: Rationale, design and methods of Baby's Breath. Contemp Clin Trials. 2017 Jan;52:1-9.

37. Zlatnik MG. Endocrine-Disrupting Chemicals and Reproductive Health. J Midwifery Women Health. 2016 Jul;61(4):442-55.

38. Barrett ES, Velez M, Qiu X, Chen SR. Reducing Prenatal Phthalate Exposure Through Maternal Dietary Changes: Results from a Pilot Study. Matern Child Health J. 2015 Sep;19(9):1936-42. 
39. Agence Régionale de Santé Nouvelle-Aquitaine. Stratégie régionale en santé environnementale autour de la petite enfance [Regional Strategy for Environmental Health around Early Childhood] 13 Feb 2019. Available from: https://www.nouvelle-aquitaine.ars.sante.fr/strategie-regionale-en-santeenvironnementale-autour-de-la-petite-enfance [Accessed 27 Jul 2020].

40. Bourguignon JP, Parent AS, Kleinjans JCS, Nawrot TS, Schoeters G, Van Larebeke N. Rationale for Environmental Hygiene towards global protection of fetuses and young children from adverse lifestyle factors. Environ Health. 2018 Apr 23;17(1):42. doi: 10.1186/s12940-018-0385-y.

41. Polinski KJ, Dabelea D, Hamman RF, Adgate JL, Calafat AM, Ye X, Starling AP. Distribution and predictors of urinary concentrations of phthalate metabolites and phenols among pregnant women in the Healthy Start Study. Environ Res. 2018 Apr;162:308-317.

42. IREPS (Instance Régionale d'Education et de Promotion de la Santé) Nouvelle-Aquitaine. Workshop 19, a pedagogical housing on environment-health. [L'atelier du 19, un logement pédagogique environnement-santé]. Available from: https://irepsna.org/actions/latelier-du-19/ [Accessed 27 Jul 2020].

43. Rouillon S, Deshayes-Morgand C, Enjalbert L, Rabouan S, Hardouin JB; Group DisProSE, Migeot V, Albouy-Llaty M. Endocrine Disruptors and Pregnancy: Knowledge, Attitudes and Prevention Behaviors of French Women. Int J Environ Res Public Health. 2017 Sep 6;14(9).

44. Rouillon S, El Ouazzani H, Rabouan S, Migeot V, Albouy-Llaty M. Determinants of Risk Perception Related to Exposure to Endocrine Disruptors during Pregnancy: A Qualitative and Quantitative Study on French Women. Int J Environ Res Public Health. 2018 Oct 11;15(10). pii: E2231. doi: 10.3390/ijerph15102231.

45. Albouy-Llaty M, Rouillon S, El Ouazzani H, DisProSE G, Rabouan S, Migeot V. Environmental Health Knowledge, Attitudes, and Practices of French Prenatal Professionals Working with a Socially Underprivileged Population: A Qualitative Study. Int J Environ Res Public Health. 2019 Jul 16;16(14). pii: E2544. doi: 10.3390/ijerph16142544.

46. Michie S, Richardson M, Johnston M, Abraham C, Francis J, Hardeman W, Eccles MP, Cane J, Wood $\mathrm{CE}$. The behavior change technique taxonomy ( $\mathrm{v} 1)$ of 93 hierarchically clustered techniques: building an international consensus for the reporting of behavior change interventions. Ann Behav Med. 2013 Aug;46(1):81-95.

47. Sørensen K, Van den Broucke S, Fullam J, Doyle G, Pelikan J, Slonska Z, Brand H; (HLS-EU) Consortium Health Literacy Project European. Health literacy and public health: a systematic review and integration of definitions and models. BMC Public Health. 2012 Jan 25;12:80.

48. Albouy-Llaty M, Dupuis A, Grignon C, Strezlec S, Pierre F, Rabouan S, Migeot V. Estimating drinkingwater ingestion and dermal contact with water in a French population of pregnant women: the EDDS cohort study. J Expo Sci Environ Epidemiol. 2015 May;25(3):308-16.

49. Vallieres EF, Vallerand RJ. Traduction et validation canadienne-française de l'échelle de l'estime de soi de Rosenberg [The Rosenberg's self-esteem scale - French-Canadian translation and validation]. Int J Psychol. 1990;(25):305-316. 2005.Available from: 
50. Célant N, Guillaume S, Rochereau T. L'Enquête santé européenne - Enquête santé et protection sociale (EHIS-ESPS) 2014 [The European Health Survey - Health and Social Protection Survey 2014]. Les rapports de l'IRDES. Sept 2017;566. 2017.

51. Enquête Nationale Périnatale (ENP) - Les NAISSANCES en 2010 et leur évolution depuis 2003. May 2011. Available from: http://solidaritessante.gouv.fr/IMG/pdf/Les_naissances_en_2010_et_leur_evolution_depuis_2003.pdf[Accessed 27 Jul 2020].

52. Heaman MI, Gupton AL. Psychometric testing of the Perception of Pregnancy Risk Questionnaire. Res Nurs Health. oct 2009;32(5):493-

53. Che S-R, Barrett ES, Velez M, Conn K, Heinert S, Qiu X. Using the Health Belief Model to Illustrate Factors That Influence Risk Assessment during Pregnancy and Implications for Prenatal Education about Endocrine Disruptors. Policy Futur Educ. 1 oct 2014;12(7):961-

54. Grignon C, Venisse N, Rouillon S, Brunet B, Bacle A, Thevenot S, et al. Ultrasensitive determination of bisphenol $A$ and its chlorinated derivatives in urine using a high-throughput UPLC-MS/MS method. Anal Bioanal Chem. 2016;408:2255-63.

55. Migeot V, Dupuis A, Cariot A, Albouy-Llaty M, Pierre F, Rabouan S. Bisphenol a and its chlorinated derivatives in human colostrum. Environ Sci Technol. 2013;47:13791-7.

56. International conference on harmonisation of technical requirements for registration of pharmaceuticals for human use. ICH Harmonised Tripartite Guideline, Validation of Analytical Procedures: Text and Methodology Q2(R1). 2005.Available from:https://database.ich.org/sites/default/files/Q2_R1_Guideline.pdf [Accessed 27 Jul 2020].

57. NORMAN, Protocol for the validation of chemical and biological monitoring methods. 2009.

58. European Medicines Agency, Committee for Medicinal Products for Human Use, Guideline on Bioanalytical Method Validation. London, United Kingdom;Available from: https://www.ema.europa.eu/en/documents/scientific-guideline/guideline-bioanalytical-methodvalidation_en.pdf [Accessed 27 Jul 2020].

59. S. Department of Health and Human Services. Food and Drug Administration (FDA). Center for Drug Evaluation and Research (CDER). Center for Veterinary Medicine (CVM). Guidance for industry: Bioanalytical Method Validation. Rockville:Maryland;May 2001.

60. Glasgow RE, Vogt TM, Boles SM. Evaluating the public health impact of health promotion interventions: the RE-AIM framework. Am J Public Health. 1999 Sep;89(9):1322-7.

61. Ribreau L. Environmental Health Education Workshops in the PREVED Study: Pregnancy, Prevention, Endocrine Disruptors [Ateliers d'éducation pour la santé environnementale dans le cadre de l'étude PREVED: Pregnancy, Prevention, Endocrine Disruptors]. [Master's degree in midwifery]. Poitiers, France: University of Poitiers;

62. Charlet Neveur M. Prevention and promotion actions for environmental health - The example of PREVED, analysis of the action "my house, my health environment" [Les actions de prévention et de promotion en santé environnementale - L'exemple de PREVED, analyse de l'action "ma maison, mon 
environnement santé"]. [Master's degree in Public Health]. Le Kremlin Bicêtre, France: Université Paris Sud;

63. Ottawa Statement from the Sparking Solutions Summit on Population Health Intervention Research: Ottawa, Ontario, Canada April 25, 2016. Can J Public Health. 2016 Nov;107(6):e492-e496.

64. Jackson SF. Global health promotion and population health intervention research. Glob Health Promot. 2017 Sep;24(3):3-4.

65. Moore G, Cambon L, Michie S, Arwidson P, Ninot G, Ferron C, Potvin L, Kellou N, Charlesworth J, Alla F; Discussion Panel. Population health intervention research: the place of theories. Trials. 2019 Jun 11;20(1):285. doi: 10.1186/s13063-019-3383-7.

66. Cambon L, Alla F. Current challenges in population health intervention research. J Epidemiol Community Health. 2019 Jul 17. pii: jech-2019-212225.

67. Rudel RA, Gray JM, Engel CL, Rawsthorne TW, Dodson RE, Ackerman JM, Rizzo J, Nudelman JL, Brody JG. Food packaging and bisphenol A and bis(2-ethyhexyl) phthalate exposure: findings from a dietary intervention. Environ Health Perspect. 2011 Jul;119(7):914-20.

68. Harley KG, Kogut K, Madrigal DS, Cardenas M, Vera IA, Meza-Alfaro G, She J, Gavin Q, Zahedi R, Bradman A, Eskenazi B, Parra KL. Reducing Phthalate, Paraben, and Phenol Exposure from Personal Care Products in Adolescent Girls: Findings from the HERMOSA Intervention Study. Environ Health Perspect. 2016 Oct;124(10):1600-1607.

69. Hagobian T, Smouse A, Streeter M, Wurst C, Schaffner A, Phelan S. Randomized Intervention Trial to Decrease Bisphenol A Urine Concentrations in Women: Pilot Study. J Womens Health (Larchmt). 2017 Feb;26(2):128-132.

70. Sathyanarayana S, Alcedo G, Saelens BE, Zhou C, Dills RL, Yu J, Lanphear B. Unexpected results in a randomized dietary trial to reduce phthalate and bisphenol A exposures. J Expo Sci Environ Epidemiol. 2013 Jul;23(4):378-84.

71. Fisher M, Arbuckle TE, Mallick R, LeBlanc A, Hauser R, Feeley M, et al. Bisphenol A and phthalate metabolite urinary concentrations: Daily and across pregnancy variability. J Expo Sci Environ Epidemiol. 2015;25:231-9.

72. Jusko TA, Shaw PA, Snijder CA, Pierik FH, Koch HM, Hauser R, et al. Reproducibility of urinary bisphenol A concentrations measured during pregnancy in the Generation R Study. J Expo Sci Environ Epidemiol. 2014;24:532-6.

73. Smith KW, Braun JM, Williams PL, Ehrlich S, Correia KF, Calafat AM, et al. Predictors and variability of urinary paraben concentrations in men and women, including before and during pregnancy. Environ Health Perspect. 2012;120:1538-43.

74. Braun JM, Smith KW, Williams PL, Calafat AM, Berry K, Ehrlich S, et al. Variability of urinary phthalate metabolite and bisphenol A concentrations before and during pregnancy. Environ Health Perspect. 2012;120:739-45.

75. Dewalque L, Pirard C, Vandepaer S, Charlier C. Temporal variability of urinary concentrations of phthalate metabolites, parabens and benzophenone-3 in a Belgian adult population. Environ Res. 
2015;142:414-23.

76. Lassen TH, Frederiksen H, Jensen TK, Petersen JH, Main KM, Skakkebæk NE, et al. Temporal variability in urinary excretion of bisphenol $A$ and seven other phenols in spot, morning, and 24-h urine samples. Environmental Research. 2013;126:164-70.

77. Nohr EA, Liew Z. How to investigate and adjust for selection bias in cohort studies. Acta Obstet Gynecol Scand. 2018 Apr;97(4):407-416.

78. Nilsen RM, Vollset SE, Gjessing HK, Skjaerven R, Melve KK, Schreuder P, Alsaker ER, Haug K, Daltveit AK, Magnus P. Self-selection and bias in a large prospective pregnancy cohort in Norway. Paediatr Perinat Epidemiol. 2009 Nov;23(6):597-608.

79. Beck E, Lechner A, Schaefer C. Who seeks Teratology Information Service's advice? Assessing the risk of selection bias in observational cohort studies on drug risks in pregnancy. Reprod Toxicol. 2017 Jan;67:79-84.

80. Vogel JM. Perils of paradigm: Complexity, policy design, and the Endocrine Disruptor Screening Program. Environ Health. 2005;4:2.

81. French Republic. Loi constitutionnelle $n^{\circ}$ 2005-205 du 1er mars 2005 relative à la Charte de l'environnement. Version consolidée au 25 juillet 2019. NOR: JUSX0300069L.

82. Cambon L, Terral P, Alla F. From intervention to interventional system: towards greater theorization in population health intervention research. BMC Public Health. 2019;19(1):339.

\section{Figures}

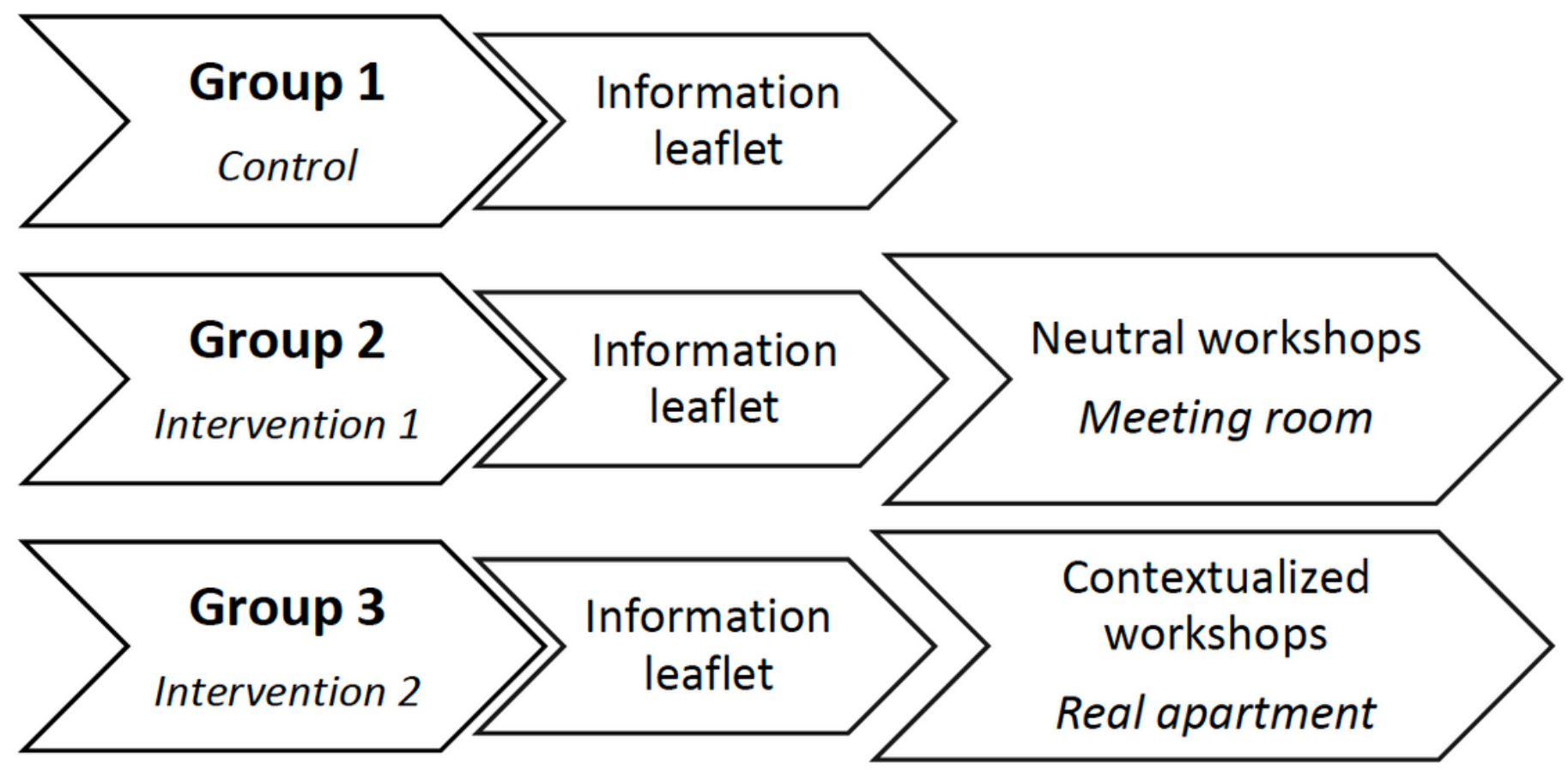


Figure 1

Description of the three groups of the PREVED study

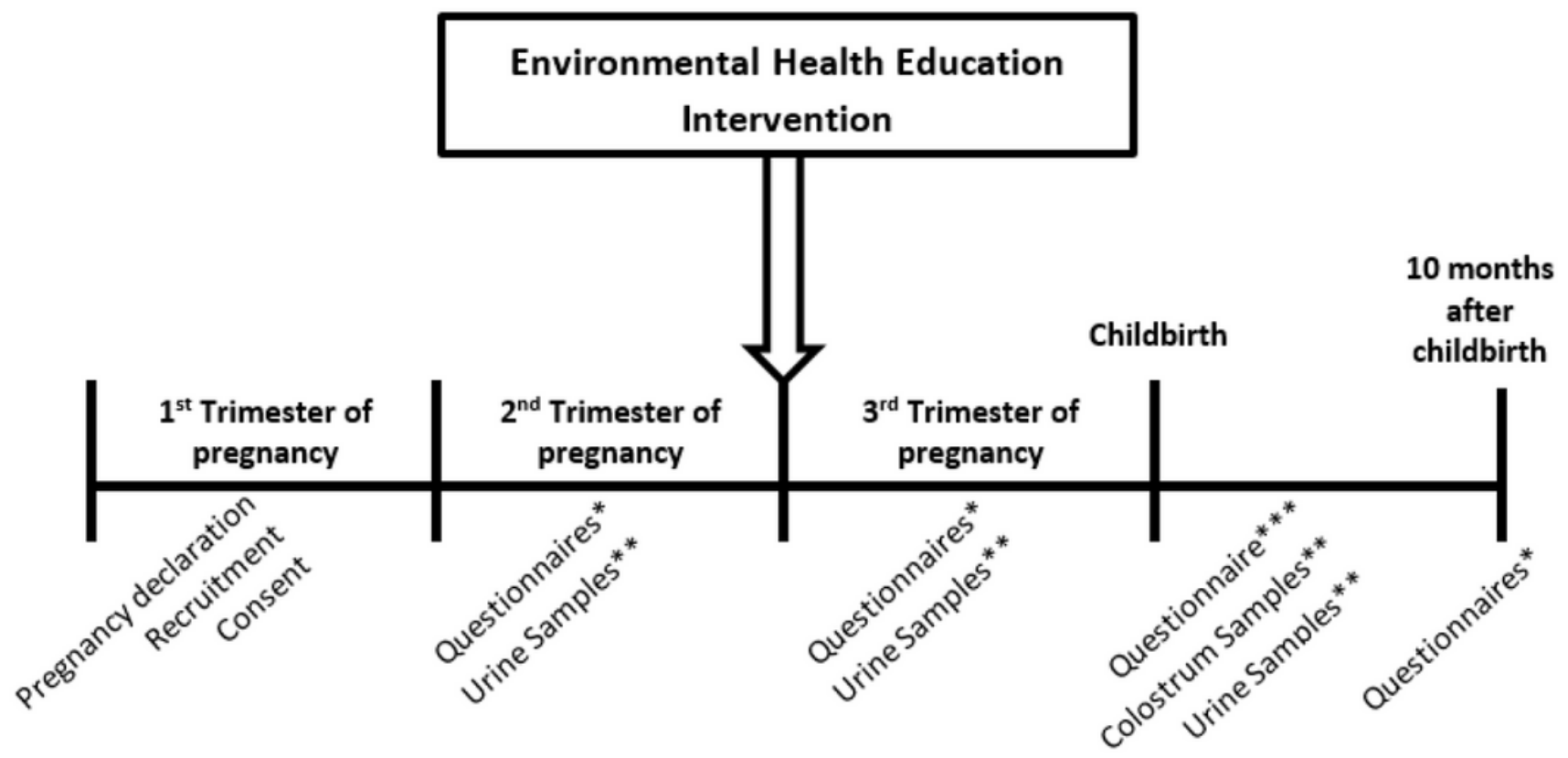

* Psychological sociodemographic and consumption questionnaires

** Determination of bisphenol A and parabens

*** Data from delivery and colostrum sampling conditions

Figure 2

Course of the PREVED study

\section{Supplementary Files}

This is a list of supplementary files associated with this preprint. Click to download.

- Additionalfile1.pdf

- Additionalfile2V4.docx

- Additionalfile3.pdf 